\title{
Study of the reliability of corroded pipeline by the ASME B31G method
}

\author{
Belaid Salim $^{1 *}$, Pascale Balland ${ }^{2}$, Maati Ahmed ${ }^{1}$, Benchatti Ahmed $^{1}$ \\ ${ }^{1}$ Mechanical laboratory, Mechanical department, University Amar Telidji, Laghouat 03000, Algeria \\ ${ }^{2}$ Univ. Savoie Mont Blanc, SYMME, FR-74000 Annecy, France
}

Corresponding Author Email: bl4salim@gmail.com

\section{https://doi.org/10.18280/mmc_b.870405}

Received: 13 July 2018

Accepted: 17 September 2018

\section{Keywords:}

steel 5LX60, probability, ASME B31G

method, pitting corrosion

\begin{abstract}
This work concerns the study of the reliability of 5LX60 steel pipes for the transport of gas under the effect of corrosion failures, particularly corrosion peaks. The objective is to determine the life time of the pipes by estimating the probability of failure based on a parametric approach where the variables are considered. Initially, an ASME B31G-based calculation model is used to calculate the operating safety pressures in the corroded pipes. This method is usually deterministic. The application of a probabilistic method implies the knowledge of the variables and the dimensions, and which give us the reliability of the models used to calculate the pressures.
\end{abstract}

\section{INTRODUCTION}

Localized failures that are manifested by pitting corrosion depth and propagating surface and cracking phenomena are major risks to the integrity of transmission systems, pipelines and the safe transport of hydrocarbons. Recent works [1-2] have shown that steels used for pipelines has been modified so that their mechanical properties are improved; a higher yield strength of HSLA steels is obtained by refinement of ferritic grains following patterns of metallurgical processes such as TMCP (Thermo-Mechanical Controlled Processing) [3].

The remaining life after localized failure (lifetime) is estimated by applying the model B31G [5-6], and a mechanical coupling fabulist. This approach has uncertainties of calculation parameters through their probability distribution of a structure such as steel pipe having degraded localized corrosion [7-8, 12]. We are interested in this work to the line GZ1 40 that connects the gas field of Hassi R'Mel in the industrial area of Arzew; all along a distance of $507 \mathrm{~km}$ were localized failures that have been revealed after thirty years of service [11].

Reliability estimation is defined as the ability of a device, or any system, to perform the required functions during a given period of time when the risk of failure is reduced; it is an approximation of the time before the probability of tube damage. It is realized using the mechano-reliability coupling model with PHIMECA reliability software. It is a tool that combines a mechanical calculation procedure and a reliability calculation procedure to find the reliability index $\beta$. The aim of this work is to introduce the mechanical model of the ultimate pressure calculation in corrugated pipelines B31G and B31G modified in reliability software PHIMECA [13], the results gives the variation of 5 parameters which will be exposed later: $d, D$, Pser, Re, $t$.

What gives the interest of these variables in the computation of the ultimate pressures following the models of computation used.

\section{MATERIALS AND METHODS}

\subsection{Study of material}

The tube material has been studied by taking samples of corroded steel pipelines that are back of the station rehabilitation of corroded pipes SONATRACT (STT) [11]; determining chemical composition and mechanical properties will help us to estimate reliability of steel. The steels are 5LX60 of API (American Petroleum Institute). Chemical composition is shown in Table 1.

Table 1. Chemical composition (API 5LX60 steel)

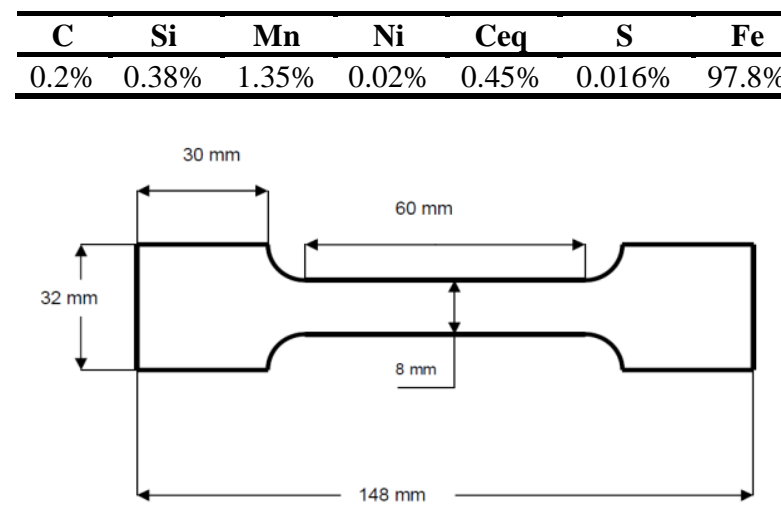

Figure 1. Specimen of longitudinal tensile test

Table 2. Mechanical properties (API 5LX60 steel)

\begin{tabular}{ccccc}
\hline Tests & $\begin{array}{c}\text { Elastic limit } \\
\text { Rp..2 }\end{array}$ & $\begin{array}{c}\text { Maximum } \\
\text { strength } \\
\mathbf{R}_{\mathbf{m}} \text { (MPa) }\end{array}$ & $\begin{array}{c}\text { Elongation } \\
(\mathbf{\%})\end{array}$ & $\begin{array}{c}\text { Necking } \\
\mathbf{Z} \%\end{array}$ \\
\hline 1 & 410 & 557 & 32.43 & 49 \\
2 & 413 & 569 & 30.84 & 53 \\
3 & 417 & 578 & 31.96 & 55 \\
Average & $\mathbf{4 1 3 . 3 3}$ & $\mathbf{5 6 8}$ & $\mathbf{3 1 . 7 4}$ & $\mathbf{5 2 . 3 3}$ \\
\hline
\end{tabular}


Tensile tests have been achieved on specimens shown in Figure 1 to determine the mechanical properties of the material after 30 years of service given in Table 2 .

Charpy tests (impact resistance) at 3 different temperatures $\left(-10^{\circ} \mathrm{C}, 0^{\circ} \mathrm{C}\right.$ and $\left.25^{\circ} \mathrm{C}\right)$ have been realized, results are summarized in Table 3.

Table 3. Results of impact tests (Charpy)

\begin{tabular}{cccccc}
\hline $\begin{array}{c}\text { Temperature } \\
\left({ }^{\circ} \mathbf{C}\right)\end{array}$ & $\begin{array}{c}\text { Test } \\
\text { tube }\end{array}$ & $\begin{array}{c}\text { Longitudinal } \\
\text { test } \\
(\text { Joule) }\end{array}$ & Average & $\begin{array}{c}\text { Transversal } \\
\text { test } \\
(\text { Joule) }\end{array}$ & Average \\
\hline \multirow{2}{*}{10} & 1 & 56 & & 95 & \\
& 2 & 46 & 53.33 & 134 & 112 \\
& 3 & 58 & & 107 & \\
\hline \multirow{2}{*}{0} & 1 & 57 & & 158 & \\
& 2 & 62 & 57 & 162 & 138 \\
& 3 & 52 & & 94 & \\
\hline \multirow{2}{*}{25} & 1 & 76 & & 148 & \\
& 2 & 88 & 83 & 164 & 160 \\
& 3 & 84 & & 166 & \\
\hline
\end{tabular}

\subsection{Mechanical model}

The B31G model was developed at the Battelle Memorial Institute, in collaboration with the American Gas Association (AGA), with the aim of limiting the extended form of imperfection, localized or generalized corrosion defects in steel pipe systems, [12] by theoretical studies and experimental analyses. For pressurized pipelines, the surface corrosion defects are measured by a so called intelligent tool (MFL Detector) that needs different dimensions of the geometry of the corrosion defect that is presented in Figure 2.

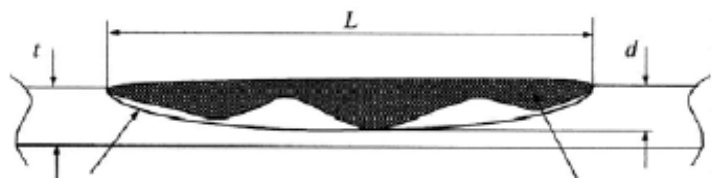

Figure 2. Section through pipe wall showing the geometry of an idealized defect

where $\mathbf{t}$ is the pipe wall thickness, $\mathbf{d}$ is the defect depth and $\mathbf{L}$ is the defect length on the surface.

According to ASME code B $1 \mathrm{G}$, the equation of corroded tube rupture is established from the experimental data and expressed from the two conditions:

1. The maximum overall circumferential stress cannot exceed the elastic limit of the material.

2. A short corrosion defect is linked to its projection in a parabolic form, and a long corrosion defect is projected in a rectangular shape.

To apply this criterion, a condition is needed: the maximum peak depth (d) should not exceed $80 \%$ of the nominal thickness, that is to say: $\mathrm{d}<0.8$.t.

The summary of the B31G model is given in eqs (1) to (13).

$S_{F}=\bar{S}\left[\frac{1-\frac{A}{A_{0}}}{1-\left(\frac{A}{A_{0}}\right) M^{-1}}\right]$

$A=\left(\frac{2 . L . d}{3}\right)$

$\mathrm{A}_{0}=\mathrm{L} . \mathrm{t}$ where, $\mathbf{d}$ is depth of the defect; L length of the defect; $t$ the thickness of the wall; M Follia's factor; A missing metal zone; $\mathrm{A}^{0}$ original cross-section; $\overline{\boldsymbol{S}}$ material flew stress area; $\mathrm{S}_{\mathrm{F}}$ Hoop stress at failure. Follia's factor is calculated according to the size of the defect, the geometrical form of the corrosion:

$\mathrm{M}_{1}=\left[1+0.6275 \frac{\mathrm{L}^{2}}{\mathrm{Dt}}-0.003375 \frac{\mathrm{L}^{4}}{\mathrm{D}^{2} \mathrm{t}^{2}}\right]$ for $\frac{L^{2}}{D t} \geq 50$

$M_{2}=0.0032 \frac{L^{2}}{D t}+3.3$ for $\frac{L^{2}}{D t}<50$

$\bar{S}=R e+68.95 \mathrm{MPa}$

where Re is specific minimum yield strength of the material. If the defect is short, we have the parabolic shape:

$$
\begin{aligned}
& \text { if } \sqrt{0.8\left(\frac{2 c}{\text { Dext }}\right)^{2}\left(\frac{\text { Dext }}{t}\right)} \leq 4 \\
& \text { Pult }=\frac{2(1.1 \operatorname{Re}) \cdot t}{\text { Dext }}\left[\frac{(1-0.66(d / t))}{\left(1-0.66(d / t) \cdot M^{-1}\right)}\right]
\end{aligned}
$$

where Dext is outside diameter of the tube; Pult maximum is pressure of the fluid in a corroded pipe.

And if the default is long, it has a rectangular shape

$$
\begin{aligned}
& \text { if } \sqrt{0.8\left(\frac{2 c}{\text { Dext }}\right)^{2}\left(\frac{\text { Dext }}{t}\right) \succ 4 \quad \text { Then pressure: }} \\
& \text { Pult }=\frac{2\left(\sigma_{\text {ultim }}\right) \cdot t}{\text { Dext }-t}\left[\frac{(1-(d / t))}{\left(1-(d / t) \cdot M^{-1}\right)}\right]
\end{aligned}
$$

where $\boldsymbol{\sigma}_{\text {ultim }}$ maximum stress of the material. According to ASME code B31G, the equation of corroded tube rupture is established from experimental data as:

$\overline{\mathrm{S}}=1.1 \mathrm{Re}+69 \mathrm{MPa}$

Also in this criterion one has two cases to consider:

Parabolic defect, $1^{\text {st }}$ case:

$\left(\frac{2 \mathrm{~L}}{\text { Dext }}\right)^{2}\left(\frac{\text { Dext }}{\mathrm{t}}\right) \leq 50$

Then pressure:

Pult $=\frac{2(1,1 R e+69) \cdot t}{\operatorname{Dext}}\left[\frac{\left(1-0,85\left(\frac{d}{t}\right)\right)}{1-0.85\left(\frac{d}{t}\right) \cdot M_{1}^{-1}}\right]$

Rectangular defect, $2^{\text {nd }}$ case:

$\left(\frac{2 L}{D e x t}\right)^{2}\left(\frac{\text { Dext }}{t}\right)>50$

Then pressure:

Pult $=\frac{2(R e) \cdot t}{\text { Dext-t }}\left[\frac{\left(1-\left(\frac{d}{t}\right)\right)}{1-\left(\frac{d}{t}\right) \cdot M_{2}^{-1}}\right]$ 
The actual data from the corrosion peaks allow us to assess the overall axial and circumferential extent of each distinct area of metal loss. There are two main decisions to make based on the depth of the defect [6].

On the one hand, if the depth of the deepest defect $d$ is less than or equal to $20 \%$ of the nominal wall thickness $t$, and the minimum wall thickness $(\mathrm{t}-\mathrm{d})$ is at least $80 \%$ from the thickness of the containing segment, it is concluded that the area is acceptable for continuous service.

On the other hand, if the depth of the deepest defect $\mathrm{d}$ is more than $80 \%$ of the thickness of the original wall, the segment containing the metal loss zone must be replaced or repaired.

\subsection{Default detection}

The detection of corrosion pits on the part of the line to study pipelines was carried out by an acoustic probe. Some results are presented in Table 4; depths are given in \% with respect to the thickness of the pipeline, and the distances of the peaks compared to the starting point are given both in absolute and relative. The statistics are computer-processed and injected into a FORTRAN language program developed to calculate the ultimate pressure for each area of the line.

Table 4. Some corrosion peak values taken from the online GZ1

\begin{tabular}{cccc}
\hline $\begin{array}{c}\text { Relative } \\
\text { distance } \\
(\mathbf{m})\end{array}$ & $\begin{array}{c}\text { Absolute } \\
\text { distance } \\
(\mathbf{m})\end{array}$ & $\begin{array}{c}\text { Max. default } \\
\text { depth d } \\
(\%)\end{array}$ & $\begin{array}{c}\text { Default length } \\
\mathbf{L}(\mathbf{m m})\end{array}$ \\
\hline 0.6 & 50.9 & 12 & 24 \\
1.9 & 52.2 & 14 & 33 \\
2.8 & 64.8 & 13 & 17 \\
5.7 & 67.7 & 18 & 85 \\
2.6 & 122.8 & 30.2 & 54 \\
7.3 & 202.1 & 13 & 125 \\
10.9 & 395.8 & 28 & 62 \\
2.7 & 589 & 35 & 37 \\
3 & 734.4 & 41.5 & 315 \\
\hline
\end{tabular}

The following figures Figure 3 show the variation of depths and languor of the corrosion defects found by the during the inspection of the gas line GZ1.
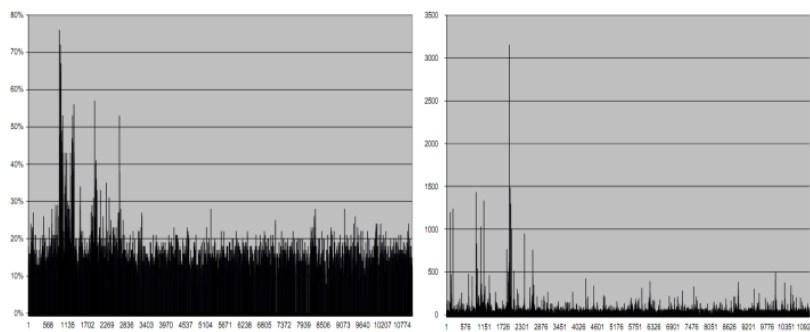

Figure 3. a. Changes in the depth of peak (\%)/ check languor of pipe $(\mathrm{m})$; b. Variations of peak languor $(\mathrm{mm}) /$ check languor of pipe $(\mathrm{m})$

To obtain such graphs, we have developed a flow chart, which is followed by a FORTRAN program to calculate the maximum service for each case of corrosion. The main program that is both subroutines $\mathrm{B} 31 \mathrm{G}$ and $\mathrm{B} 31 \mathrm{G}$ modified to calculate the final pressure in corroded pipes, gives us the possibility of continued operation of pipelines or permanent repair or replacement. In what follows Table 5, we give some values issued from our program, the ultimate pressure for different depths of peaks above $40 \%$ of the thickness of the pipe.

Table 5. Ultimate pressures calculated by the program for various craters

\begin{tabular}{|c|c|c|c|c|c|c|}
\hline $\begin{array}{c}\text { Deep } \\
\text { d } \\
(\%)\end{array}$ & $\begin{array}{c}\text { Deep } \\
\mathbf{d} \\
(\mathrm{mm})\end{array}$ & $\begin{array}{c}\text { Length } \\
\mathbf{L} \\
(\mathbf{m m})\end{array}$ & $\begin{array}{c}\text { Pressure } \\
\text { B31G } \\
\text { (Bar) }\end{array}$ & & $\begin{array}{l}\text { Pressure } \\
\text { B31G } \\
\text { modified } \\
\text { (Bar) } \\
\end{array}$ & Observation \\
\hline $40 \%$ & 5.08 & 1484 & 28.31 & 25.73 & 3 Replace & \\
\hline $43 \%$ & 5.461 & 284 & 32.74 & 34.73 & & \\
\hline $46 \%$ & 5.842 & 118 & 36.21 & 39.80 & & \\
\hline $47 \%$ & 5.969 & 127 & 35.98 & 38.51 & & \\
\hline $48 \%$ & 6.096 & 537 & 26.59 & 30.39 & & \\
\hline $49 \%$ & 6.223 & 207 & 32.89 & 34.91 & & \\
\hline $50 \%$ & 6.35 & 457 & 29.70 & 30.22 & & \\
\hline $53 \%$ & 6.731 & 556 & 24.33 & 28.47 & 7 Replace & \\
\hline $54 \%$ & 6.858 & 86 & 36.9 & 40.69 & & \\
\hline $57 \%$ & 7.239 & 3152 & 19.73 & 17.96 & 6 Replace & \\
\hline $60 \%$ & 7.62 & 395 & 27.78 & 27.22 & 2 Repair & \\
\hline $67 \%$ & 8.5 & 142 & 31.98 & 33.04 & & \\
\hline $72 \%$ & 9.144 & 829 & 14.72 & 13.38 & 8 Replace & \\
\hline $76 \%$ & 9.652 & 1430 & 11.88 & 10.80 & 0 Replace & \\
\hline
\end{tabular}

\section{PIPELINE REMAINING LIFE ASSESSMENT}

\subsection{Reliability index $\beta$ and the pipeline failure pressure Pfp $[4 ; 10 ; 14]$}

The reliability software PHIMECA [13] is used to compute the reliability index $\beta$ and the pipeline failure pressure Pfp: it is reliability model of B31G in PHIMECA.

We directly introduced our mechanical model of B31G in the software, then we made the different parameters vary, we chose the parameters: a, D, Pser, Re, $t$ values which change in the iteration of calculates by $5 \%$ of each value (we chose 100 iterations), in order to see the different influences in the results. The calculation model is based on the principle of the Cornell Reliability which consists in measuring the distance between the average point of the margin $\mathrm{G}(\mathrm{Xi})$ and the point where the margin becomes naught (point of failure), this distance is measured in number of standard deviations. In other words, to assess the reliability, we determine how many standard deviations separate the average operating state from the one of failure.

Figure 4 below presents the mechanical model introduced in PHIMECA.

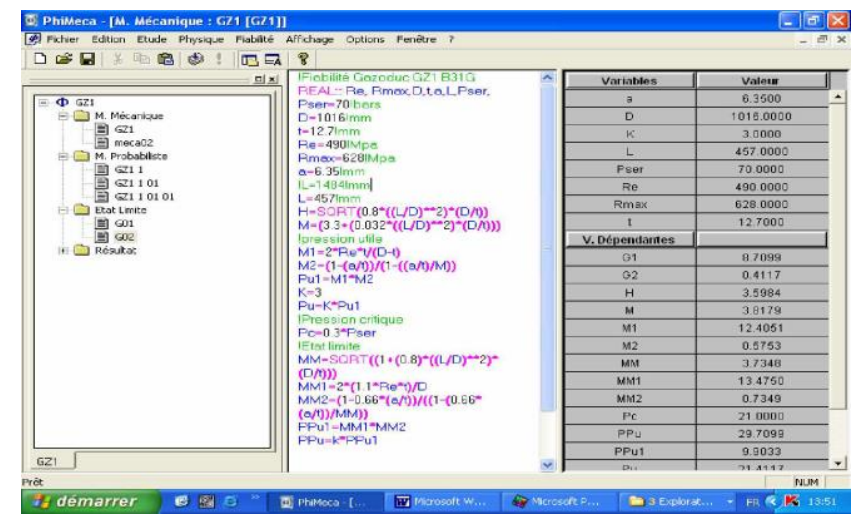

Figure 4. Reliability model of B31G in PHIMECA 
The probability of failure is expressed by the reliability index $\beta$. This index provides values that should be then compared with acceptable values [1]. In the case of mechanical structures, this index is of the order of 3.723 and it corresponds to a probability of failure of $10^{-4}$. Above this value, the structure works in a security domain, below it is failing. Table 6 shows the variation of the reliability index with respect to the length of the corrosion defect.

Table 6. Variation of the coefficients introduced in the reliability model

\begin{tabular}{ccccc}
\hline Symbols & \multicolumn{2}{c}{ B31G } & B31G & Modify \\
\hline Limit state & G1 & G2 & G3 & G4 \\
\hline $\begin{array}{l}\text { Defect length } \\
\text { L (mm) }\end{array}$ & $0-508$ & $508-1438$ & $0-589$ & $589-1438$ \\
\hline $\begin{array}{c}\text { Defect depth } \\
\text { d (\%) }\end{array}$ & $20 \%-72 \%$ & $20 \%-72 \%$ & $20 \%-72 \%$ & $20 \%-72 \%$ \\
\hline
\end{tabular}

The limit state function or performance function can be defined as the difference between the pipeline failure pressure Pfp and the pipeline operating pressure Pop. This formula gives us the variation of pressure with respect to different parameter changes, especially the peak corrosion parameters (peak depth and peak width). Uncertainties are taken into account in the probabilistic model. Calculations take precedence over the variation in pressure, length and depth of peaks [9]. For peak depths of $20 \%$ to $50 \%$ of the thickness of the pipe, length varies between $8 \mathrm{~mm}$ and $804 \mathrm{~mm}$. Then, the calculations give the following results given in Figure 5.

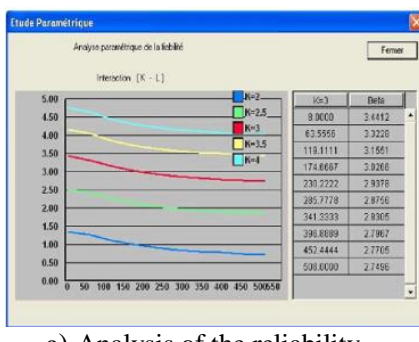

a)-Analysis of the reliability (d $=20 \% \mathrm{t}, \mathrm{L}=8-608 \mathrm{~mm}, \mathrm{~B} 31 \mathrm{G})$

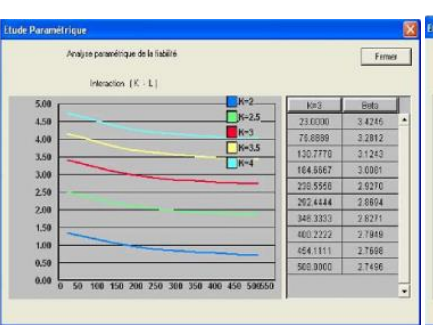

(c)-Analysis of the reliability (d $=40 \% \mathrm{t}, \mathrm{L}=23-508 \mathrm{~mm}, \mathrm{~B} 31 \mathrm{G})$

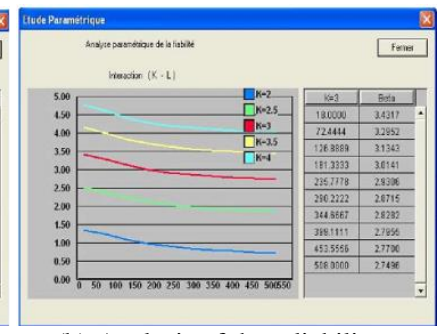

(b)-Analysis of the reliability (d $=30 \% \mathrm{t}, \mathrm{L}=18-808 \mathrm{~mm}, \mathrm{~B} 31 \mathrm{G})$

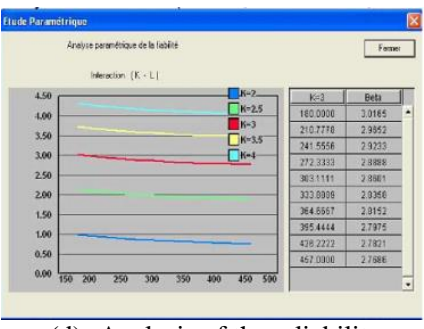

(d)- Analysis of the reliability (d $=50 \% \mathrm{t}, \mathrm{L}=18-808 \mathrm{~mm}, \mathrm{~B} 31 \mathrm{G})$
Figure 5. Reliability results for varying the length $\mathrm{L}$ with the code B31G

These figures show the variation of the reliability index $\beta$, for a safety factor increasing from $\mathrm{k}$ varied 2 to 4 . However, the length of the peak plays a considerable role. The values $\beta$ remain in the safety range up to $\mathrm{L}=200 \mathrm{~mm}$ for $\mathrm{k}=3.5$. For low safety factors, the pipe tends to work in the failing domain. So there is a great deal of uncertainty about its resistance. Figure 6 illustrates the effect of defect length on the reliability index $\beta$, for different defect depths.

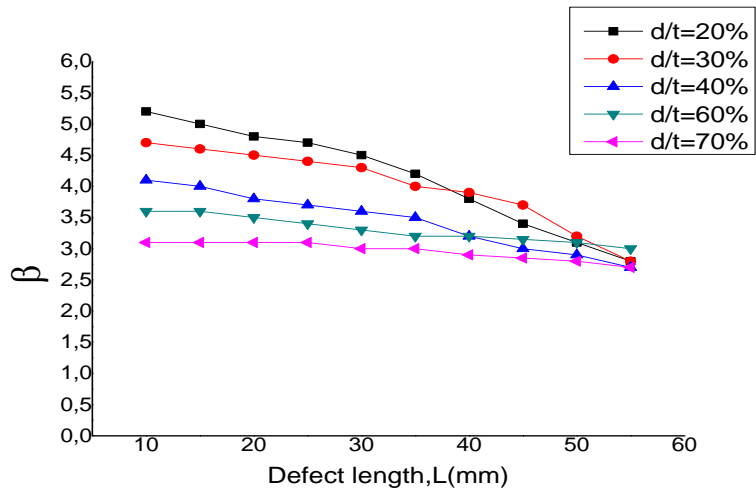

Figure 6. Effect of peak length $L$ on reliability index $\beta$

The acceptable value of $\beta$ equals to 3.7272 , which is used in petroleum structures, we can discuss this value. The discussion can be divided into two parts depending on the depth / thickness ratio $\mathrm{d} / \mathrm{t}$; when $\mathrm{d} / \mathrm{t}$ is greater than $30 \%$, the failure domain is reached, and when $\mathrm{d} / \mathrm{t}$ is less than $30 \%$, the behavior depends on the length of the defect. The present study stops after only $52 \mathrm{~mm}$ pit length when $\beta$ decreases drastically. The depth of the peak $d$ has a great influence on the safety of the corroded pipe, but this influence increases with the length and also elevates the depth from which a very high risk of sudden failure as presented in Figure 7.

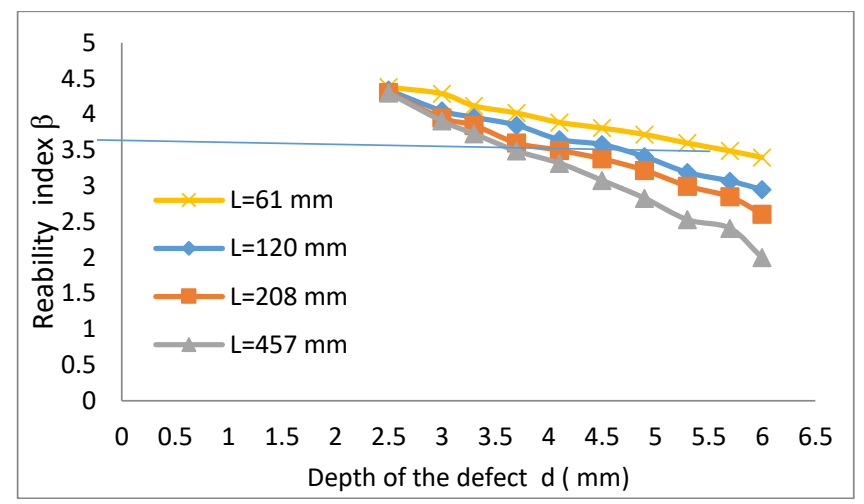

Figure 7. Variation of reliability $\beta$ by different depth $d$ with B31G

This figure gives us the reliability interval of the corroded pipelines by choosing 4 different defect lengths and varying the depths of the peaks according to the B31G standard. It can be seen that above $3.5 \mathrm{~mm}$ for the depth of the peak if the fault length exceeds $200 \mathrm{~mm}$, the model is no longer reliable or $\beta$ decreases less than 3.7, which means a risk of a sudden rupture of the pipeline.

The proposed reliability assessment based on an acceptable reliability index $\beta$ is very objective to avoid production losses and failures that can lead to disaster if the right decision was not made at the good time.

\subsection{Parameters depending on the model B31G and B31G modify}

The parameters influencing the calculation model such as the service pressure Pse, outer diameter of the pipe D, elastic limit of the material Re, are shown in Figure 8. In this case, these diagrams show a clear change of influence from one parameter to another according to the depth of the peak. 
Besides, an example of the variation in the importance of the elastic limit $\mathrm{Re}$ of the material in our model, which is between $18 \%$ and $35 \%$ of the overall reliability of the model, is given.

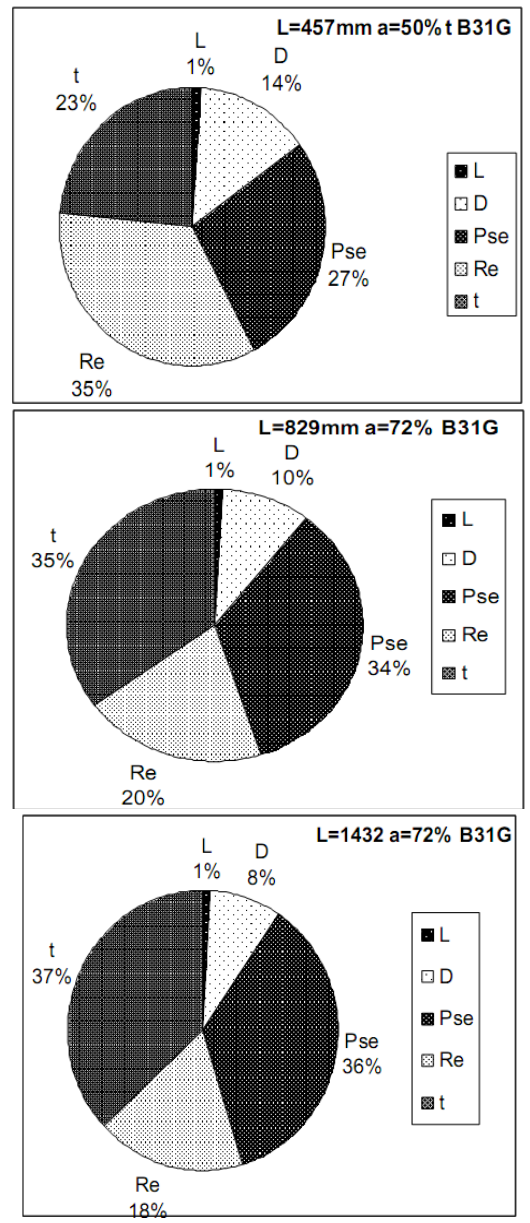

Figure 8. Distribution of reliability parameters depending on the model B31G

It can be noticed that the length of the defect is not too important in this model which varies from 1 to $3 \%$. Figure 9 shows the variation of the reliability function of these parameters. The variation of $\mathrm{L}$ gives decreasing values of the index of reliability of each time and $\mathrm{L}$ increases, but the depth $d$ has a great influence on the reliability of the pipe, the reliability index increases with the increase of the boundary strength R.

The figures show the change of the part played by the different parameters by increasing lengths and depths of the peaks; some parameters become more important than others such as operating pressure and thickness of the pipe.

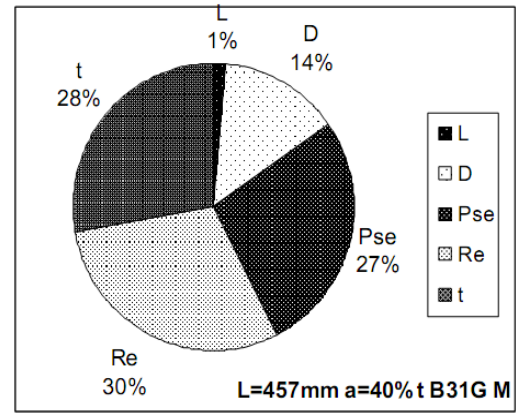

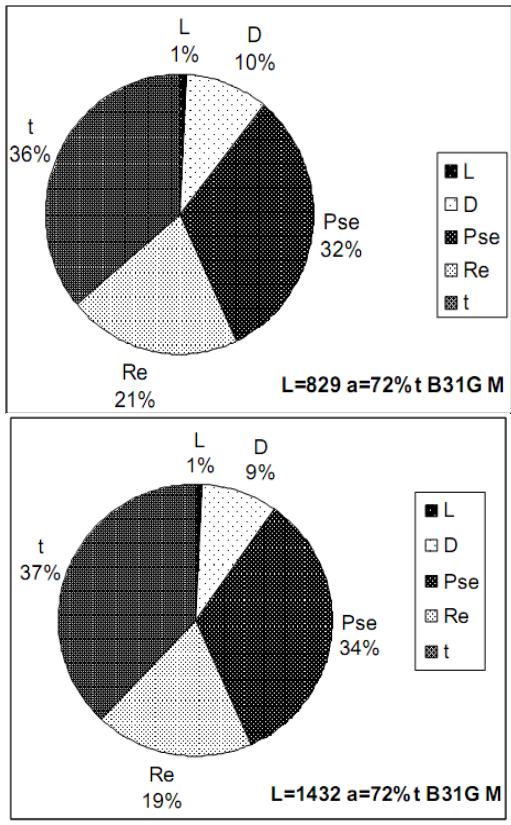

Figure 9. Distribution of reliability parameters depending on the model B31G modify

In this case, we note very well in these diagrams the change of influence from one parameter to another following the increase of the depth and the length of the peak.

The importance of the elastic limit of the material in this model varies from $19 \%$ to $35 \%$ according to the languor and the depth of the defect. The importance of the thickness $t$ varies from 28 to $35 \%$, the operating pressure from 27 to $34 \%$. When the outside diameter decreases, its importance increases to $9 \%$ with the increase of the length and depth of the defect according to the norm B31G modify. If the depth of the peak reaches $72 \%$ of $t$, one sees the increase of the importance of the percentage of the thickness $t$ and the service pressure Pse and the decrease of the influence of Re.

\section{CONCLUSIONS}

The reliability study $\mathrm{B} 31 \mathrm{G}$ showed that the reliability index is very low in many cases, where the pressure is high depending on the values calculated in the model, which has allowed us to improve reliability for the system by reducing the rates of practical failure of the corroded pipelines to estimate the best transport of hydrocarbons by pipeline. Other reliability models [15] have been developed to provide greater reliability with higher pressures that are beginning to be used in pipeline transportation.

The mechanics-reliability coupling that we established using the PHIMECA software reliability software gave us results according to the two models used showing the influence of the reliability parameters on the thickness $t$, elastic limit Re, service pressure Pser and external diameter D reliability index of pipes and its performances. Increasing the abrasion resistance of the steels of pipelines can be explained on the basis of the resistance imparted by the incorporation of the hard martensite phase in this steel [16]

These results show that the thickness $t$ which represents from 20 to $70 \%$ of the value of reliability as a function of the considered lengths and the elasticity limit between 400 and $600 \mathrm{MPa}$ are parameters which directly influence the variation of the reliability of the pipe. 


\section{ACKNOWLEDGMENT}

This research is the result of a master's thesis of Mr. Belaid Salim, held in March 2008, Department of Mechanical Engineering Faculty of Technology, University Abu Baker Belkaid Tlemcen, Algeria.

\section{REFERENCES}

[1] Maes MA, Dann M, Salama MM. (2008). Influence of grade on the reliability of corroding pipelines. Reliability Engineering and System Safety 93(3): 447455. https://doi.org/10.1016/j.ress.2006.12.009

[2] Teixeira AP, Guedes SC, Netto TA, Estefen SF. (2008). Reliability of pipelines with corrosion defects. International Journal of Pressure Vessels and Piping 85(4):

228-237. https://doi.org/10.1016/j.ijpvp.2007.09.002

[3] Aqueous Corrosion (1989). Handbook of Corrosion Engineering. Chapter 1- RAR archive.

[4] Pipeline investigation report (2003). Transportation Safety Board of Canada.

[5] Morton W. (2008). Stress Corrosion Cracking Technical Workshop Office of Pipeline Safety Research and Special Programs Administration SCC Workshop, Houston.

[6] Manual for determining the remaining strength of corroded pipelines (1991). ASME B31G code for pressure piping, New York: American Society for Mechanical Engineer.

[7] Pipeline Systems (1986). Canadian Standards Association CANICSA-ZKWM86.

[8] Ahammed M. (1998). Probabilistic estimation of remaining life of a pipeline in the presence of active corrosion defects. International Journal of Pressure Vessels and Piping 75: 321-329. https://doi.org/10.1016/S0308-0161 (98)00006-4

[9] Amirat. A., Benmoussat A., Chaoui K. (2009). Reliability Assessment of Underground Pipelines Under Active Corrosion Defects. Damage and Fracture Mechanics. SpringerLink.

[10] Shipilov SA, Iain Le May (2006). Structural integrity of aging buried pipelines having cathodic protection. Engineering Failure Analysis 13(7): 1159-1176. https://doi.org/10.1016/j.engfailanal.2005.07.008

[11] Belaid S. (2008). Analysis of the reliability of API 5L X60 steel for pipelines entered on the basis of model B31G. Magister in Mechanical Engineering. Tlemcen
University.

[12] Civallero M, Mirabile M, Sih GC. (1981). Fracture mechanics in pipeline technology. In: Analytical and Experimental Fracture Mechanics. Ed. Sih, G.C. and Mirabile M.

[13] Phimeca Engineering (2002). Reliability-based design and analysis. Users manual, Aubiere, France.

[14] Khelif R. (2007). Analyse de la rupture et évaluation de la durée de vie basée sur la fiabilité des tubes en polyéthylène. Doctoral thesis, CLERMONT II University.

[15] Seikowave INC (2017). Estimating pipeline reliability. Matt Bellis edition.

[16] Zidelmel S, Allaoui O, Allaoui L, Benchatti A. (2017). Influence of the heat treatments on martensite microstructure and abrasive wear behavior of X52 dualphase steel. Modeling, Measurement and Control B 86(3): 582-592. https://doi.org/10.18280/mmc_b.860301

\section{NOMENCLATURE}

\begin{tabular}{|c|c|}
\hline $\begin{array}{l}\mathrm{A}^{0} \text { original } \\
\text { cross-section }\end{array}$ & Missing metal zone, $\mathrm{mm}^{2}$ \\
\hline M & Follia's factor \\
\hline Pse & Service pressure, bar \\
\hline $\mathrm{L}$ & Default length, mm. \\
\hline $\mathrm{d}$ & Depth of the defect, mm \\
\hline $\mathrm{t}$ & Thickness, mm \\
\hline $\mathrm{S}_{\mathrm{F}}$ & Hoop stress at failure, $\mathrm{MPa}$ \\
\hline Pfp & Pipeline failure pressure, Bar \\
\hline Dext & Outside diameter of the tube, $\mathrm{mm}$ \\
\hline Pult & Ultime pressure, bar \\
\hline $\mathrm{Re}$ & Elastic limit, $\mathrm{MPa}$ \\
\hline
\end{tabular}

\section{Greek symbols}

$\beta \quad$ Reliability index

бultim Maximum stress of the material, MPa

$\varepsilon \quad$ True strain, $\%$

\section{Subscripts}

API American Petroleum Institute

B31G Mechanical model of the ultimate

STT Tube treatment station 